\title{
Xavier Villaurrutia, un Alto Exponente del Espíritu de Pirandello en Hispanoamérica
}

He centenario de Luigi Pirandello (n. 1867), precursor de las actuateatro de quien tanto se penetró del espíritu pirandelliano en Hispanoamérica: Xavier Villaurrutia. Los que hasta ahora han evaluado las obras de este escritor mexicano - sus conceptos y su pesimismo derivados de la soledad del hombre y de su angustiosa "búsqueda de la verdad" 1 -han hecho caso omiso de su innegable afinidad intelectual con el maestro italiano. Antes bien han soslayado la cuestión de posibles influencias literarias en Villaurrutia, pese a señalar su amplio conocimiento de los mejores escritores del mundo.2 Avido lector en varios idiomas, sus dones de herencia - el ingenio y la sutileza mexicanos- "fueron apoyados en una cultura universal constantemente renovada..."3 Con afirmar que Pirandello fue el dramaturgo predilecto de Villaurrutia, Vera F. Beck dejó una pista para los que quisieran aclarar los recursos enigmáticos a que fue tan propenso. Otros críticos han comentado esta afición, pero sin sospechar que Pirandello fuera la clave de algunos aspectos oscuros de su producción teatral.5

1 Véase el estudio de Donald L. Shaw, "Pasión y Verdad en el Teatro de Villaurrutia", Revista Iberoamericana, XXVIII, 54 (Dic. 1962), pp. 337-346.

2 Un propósito del presente estudio es precisamente suplementar mi estudio anterior sobre Villautrutia, rectificando así mi propia omisión del tan importante aspecto de sus influencias literarias, en el capítulo "Xavier Villaurrutia" de mi libro Teatro mexicano contemporáneo 1940-1962 (México, 1962), pp. 77-82.

3 Luis G. Basurto, "El teatro y la amistad en Xavier Villaurrutia", Cuaderne's de Bellas Artes (V. México, D. F., 1960), p. 13.

4 Vera F. Beck, "Xavier Villaurrutia, dramaturgo moderno", Revista Iberoamericana, XVIII, 35 (Dic., 1952), pp. 27-39.

5 De hecho Villaurrutia tradujo obras del francés, inglés y del italiano. "Luigi Pirandello was apparently his favorite among the foreign playwrights for he translated more of his plays than those of the others". Antonio Moreno, 
El poeta mexicano conoció a fondo las obras italianas que le servitían de fuente nutricia; había intervenido en su escenificación como actor y director en los teatros experimentales de la capital mexicana. Colaboró en la traducción de algunas de ellas como La vita che ti diedi, 6 cuyos principios aprovechó en su propia obra $E l$ ausente. Esta, junto con ¿En qué piensas? y Parece mentíra constituyen lo más característico de los "autos profanos", que lo distinguieron desde un principio como dramaturgo cerebral. La consideración, además, de unas comedias en tres actos: Invitación a la muerte, El yerro candente, Juego peligroso y La mujer legtitima, bastará para comprobar la influencia directa de Pirandello en Xavier Villaurrutia.

En El ausente Villaurrutia se vale de la teoría freudiana de la personalidad múltiple que introdujo Pirandello en La vita che ti diedi. Ambas obras tratan del cambio que sufre el individuo a través del tiempo. En el drama de Pirandello un hijo regresa a la casa de su madre después de siete años. Al poco de llegar, muere el hijo a consecuencia del amor adúltero que le había consumido. Pero su madre, doña Ana, no llora.

Doña Ana: ... No ha muerto ahora; por el contrario, lloré, escondida, todas mis lágrimas cuando lo vi llegar... cuando regresó otto, que ya nada tenía, nada, de mi hijo.

Don Jorge: $;$ Eso es —sí, cambiado- seguramente!.. Pero ya sabemos que la vida nos cambia y...

Doña Ana: Y nos parece que podemos consolarnos diciendo así: cambiado. Y "cambiado" no quiere decir: otro distinto de aquél que era?

(La vida que te di, p. 25).

El caso que plantea Villaurrutia en $E l$ ausente es similar. Sustituye a la madre por una esposa en espera del marido que se halla ausente, tantbién por un amor adúltero. Fernanda, la esposa, disimula su angustia y los vecinos, igualmente hipócritas, aparentan ignorar la equívoca situa-

"Xavier Villaurrutia: the Development of His Theatre", Hispania, XLIII, 4 (Dic., $1960)$, p. 509.

6 La vita che ti diedi fue traducido por $\mathrm{X}$. Villaurrutia y Agustín Lazo con el título La vida que te di (México D. F., 1940). Para esta fecha habían sido representadas en México por lo menos una docena de obras de Pirandello traducidas del italiano. Además, la llegada del mismo Pirandello a América del Sur, en 1927 y 1933 - la primera vez con su compañía italiana de Roma- estimuló una mayor difusión e interés en su teatro. Ver Marcello Mancini, "Luigi Pirandello en América Latina", Imagen (Caracas), $\mathrm{N}^{\circ} 16, \mathrm{pp} .6-7$. 
ción que guarda el marido delincuente (ser y parecer). En lo íntimo ella sabe que en cuanto regrese, ella lo perdonará como siempre, aun sabiendo que se marchará nuevamente. Mas en esta ocasión vuelve en compañia de la amante. Sólo entonces se le cae a Fernanda la venda de los ojos, borrándosele definitivamente la ilusión. El siguiente parlamento suyo recuerda al de doña Ana arriba citado:

Fernanda: No era el mismo el que volvió. ¿Le vio las manos? ¿Le vio los ojos? No eran los suyos. Y no quise dejarlo hablar para no oír su voz. Tenía miedo de que fuera la de un muerto que por un milagro hubiera resucitado. ¡Si no estoy segura de que Pedro estuviera vivo! Pero ahora sé que está muerto; que no volverá... i Ya ve que no he llorado en todo este tiempo en que estuvo lejos!?

Tanto la esposa mexicana como la madre italiana se consuelan imaginando que sus seres queridos se han muerto. Así recordarán sólo lo bueno que eran ellos antes del fatal cambio. Después doña Ana niega la muerte del hijo cuando él fallece de verdad: "... basta que esté viva la memoria, y el sueño es vida ... Mi hijo como yo lo veo: ¡vivo, vivo!" También en Fernanda la voluntad apasiona al intelecto. Ella recordará al "difunto" marido, "no ahora que vino, sino antes, y siempre!; Pedro era tan bueno, ¡tan bueno!" ( $\left(6_{7}\right.$ ). En ambas obras la realidad subjetiva anula o rectifica la realidad objetiva. ${ }^{\text {. }}$

${ }^{E n}$ 'qué piensas? entraña un complicado juego cerebral. Subtitulada "misterio", la obra no es tan obscura si se invoca la agilidad mental de Pirandello. Tres jóvenes amados por María Luisa simbolizan tres niveles de realidades coexistentes en la mente de la heroína. Ella aún ama al ex-novio (realidad del recuerdo), al novio actual (realidad presente) y al que ella intuye será su próximo novio (realidad de la imaginación).

Víctor: ¿Quieres decir que nos amas a los tres a un tiempo?

María Luisa: No como tú lo entiendes. A un tiempo, no; en el tiempo. ( 1 I3)

7 Xavier Villaurrutia, Poesía y teatro completos (Fondo de Cultura Económica: México, 1953), p. 166. Las subsiguientes citas de las obras de Villaurrutia se tomarán de esta edición y se indicarán por el número de la página entre paréntesis.

8 Juan Guerrero Zamora - Historia del teatro contemporáneo, (Barcelona, 1961), II, 214 - llama "voluntad correctora pirandelliana" a este fenómeno apreciado en La vita che ti diedi, en que el amor materno puede "matar" a un hijo que había cambiado y después de muerto darle vida otra vez. Villaurrutia también hace que Fernanda resuelva intelectivamente una situación de injusticia. 
Al final aparece un cuarto personaje, El Desconocido. El referido novio futuro se desilusiona pensando que María Luisa ha de dejarlo a él también por algún desconocido, según este juego absurdo que se renueva indefinidamente. La filosofía de esta joven coincide con el pesimismo expresado por el Padre en Sei personaggi in cerca d"autore: "Si la realidad de ayer es hoy apenas un recuerdo, hay que desconfiar de la realidad [de] hoy... pues mañana no será más que una ilusión" (Acto III). ¿En qué piensas? anticipa las últimas vanguardias, en razón de tener personajes simbólicos e irreales, así como una estructura circular que soslaya solución alguna.

En el único acto de Parece mentira, Villaurrutia reúne los más relevantes conceptos del teatro pirandelliano. Al igual que Ciascuno a suo modo, la obra mexicana comienza con una discusión sobre el carácter inconstante de las opiniones, conduciendo con ello al mismo callejón sin salida: la imposibilidad de toda gnoseología. En la obra italiana un joven le pide a un viejo su opinión sobre algo ignorado por el espectador. El viejo esquivo pregunta cómo opinan los demás; supone que los datos aportados por ellos modificarán su propio juicio. Las contradicciones de la verdad multifacética impiden que se forme una opinión. En Parece mentira Villaurrutia corrobora con un ejemplo concreto esta dialéctica pirandelliana. El Curioso desea saber si el abogado a quien espera es joven. El Empleado del bufete rehusa opinar, respondiéndole: "Mis puntos de vista son, seguramente tan diversos a los suyos, que, a lo mejor, la persona que a mí me parece joven a usted le parece un superviviente... Comparado con el señor padre del señor Fernández, el señor Fernández es joven; comparado con el hijo del señor Fernández, el señor Fernández ya no es joven" (8r).

Parece mentira asimismo se ocupa de la personalidad múltiple, tema reiterado en una y otra obra de Pirandello. En Sei personaggi... se destruye nuestra ilusión de poseer una personalidad única para todo el tiempo y para todo el mundo (Acto I). En Così è (se vi pare), Laudisi reconoce que él es una persona diferente para todos, en tanto que la Sra. Sirelli se engaña creyendo que es, fue y siempre será la misma. Al contratio, en Ciascuno a suo modo una dama confiesa desconocerse a sí misma. Le avergüenza tanto verse alternar entre la risa y el llanto, que se oculta la cara de sí misma para no ver su inconstancia (Acto I): Según Villaurrutia, esta renuncia de su multiplicidad hace que el hombre viva y muera ignorándose. El Empleado en Parece mentira dice: [EI hombre] juega consigo al escondite, y aún sabiendo dónde se oculta, no se atreve a decir 'aquí estoy' o 'aquí está el otro' " (83). 
La hipótesis en que se funda el teatro pirandelliano está basada en que el hombre no se da plena cuenta de su existencia hasta que el sufrimiento le vuelve introspectivo. Sólo entonces se despabila y empieza a verse vivir y ejercer el raciocinio que lo distingue de la bestia. ${ }^{9}$ Villaurrutia recalca esta idea en Parece mentira:

El Curioso: ¿Y si yo le dijera a usted que soy dichoso y que no necesito explicarme los tormen'os que no sufro?

E1 Empleado: Si eso fuera verdad, al declararlo no haría usted sino demostrar su inexistencia (83).

El asunto de la pieza, por inverosímil que sea, se presta al propósito ideológico de Villaurrutia. Un anónimo le revela al Marido que "con ésta será la tercera vez que su esposa visite al abogado Fernández" ( 90$)$. Al poco de acudir el Marido al bufete indicado, aparecen sucesivamente tres mujeres idénticas de velo negro. Una tras otra le entregan al Empleado una tarjeta y pasan al privado. Sin embargo, resulta que el Empleado no ha recibido sino una tarjeta; además, el Curioso es el único que pluraliza el suceso al referirse a la llegada de "las señoras". Por lo tanto, se deduce que dos de ellas han sido sólo imágenes de la memoria que guarda el Curioso de las dos previas visitas de la infiel esposa. El habrá sido, entonces, el autor del anónimo. Merced a este aviso, un marido que hábía sido tan feliz como un niño, está a punto de embarcar en una existencia que ahora podrá labrar a conciencia. "Es usted - lé advierte el Empleado - el empresario de un espectáculo en que será al mismo tiempo el creador, el actor y el espectador" (93). Más que una, mera alusión tcatral, que en sí recuerda al maestro ítalo, el término: "espectador" es significativamente pirandelliano porque implica que se: verá vivir como en un espejo.

Lo más sugestivo de la obra es la cuestión de las tres "señoras". ¿Cómo es que al final, aún sin estar presente el Curioso - cumplida su misión, se ha marchado-, pueden ellas abandonar el despacho de la misma manera que entraron? $Y$ esta vez el Marido si reacciona al enfrentarse con cada una: con la primera "esposa" se violenta; a la segunda: le suplica; pero una tras otta le huyen. Cuando está por retirarse, lai esposa misma sale. Para entonces la ira del Marido se ha transformado nuevamente en amor, mas ella se le escapa también. Sucede que las dos

9 A esta idea, expuesta en Sei personaggi in cerca d'autore (Acto III), le da amplia explicación Giuseppe Pardieri, Luigi Pirandello, il pensiero e il sentimento (Milano-Varese, 1961), pp. 38-42. 
visiones, primero nacidas de la intelección del Curioso, después cobran vida independiente en la imaginación del Marido, debido a que antes. de la salida de su esposa, pensaba en cómo había de abordarla. Los dos: primeros encuentros podrían explicarse como los "ensayos mentales", previos al "espectáculo" en sí. Es evidente que el Marido hace un papel pésimo como "empresario" de su existencia. Lo anterior es una posible interpretación de lo que Villaurrutia mismo califica como "enigma", el' que difícilmente se resolverá sin recurrir a los antecedentes pirandellianos. En Parece mentira Villaurrutia supera la cualidad cerebral de su maestro siciliano por cuanto sus imágenes subjetivas están equilibradas en un hábil juego de simetría expresionista.

Ejemplo contundente del alcance de la imaginación se da en Invitación a la mzierte, la obra mexicana más penetrada del escepticismo pirandelliano respecto a la incognoscibilidad de la verdad y la consecuente falta de comprensión entre los hombres. El personaje expositor de Villaurrutia justifica que el protagonista, Alberto, sea poco comunicativo e incluso que se hable a sí mismo: ". . es de mejor gusto que hablar con los demás" (307). Alberto padece una fiebre espiritual. propia de "un joven complicado, moderno, comido por preocupaciones y por interrogaciones; acaso el día que alguien lograra acabar con ellas sólo conseguiría hacer de él un fardo humano, un cuerpo vacío" (308), - Recuérdese que la negación de toda verdad objetiva es la médula de Così è (se vi pare), obra que alimenta a la par dos versiones contradictorias de la "verdad", sin arribar a ninguna conclusión irrefutable. Este dilema tiene su paralelo síquico en Invitación a la muerte. Siempre que Alberto, símbolo de la soledad humana, cree palpar la verdad, se le abre un nuevo abismo: ". . las más de las veces, al descorrer una cortina encuentro que delante de mí se presenta otra y otra, y que la duda sigue y que la verdad parece huir... (315). Lo único estable en su mundo escurridizo, es el recuerdo que guarda celosamente de su padre, ausente del hogar desde hace ro años. No obstante, cuando al fin regresa, el hijo lo rechaza cual impostor del recuerdo que tiene de él; la imagen es más verdadera por ser una realidad subjetiva y más fiel porque, a diferencia del padre real, jamás lo ha abandonado. Triunfa la ilusión

10 No puede uno menos de pensar que "fardo humano" y "cuerpo vacio" describen petfectamente a Stan, el antihéroe de Pinter - dramaturgo inglés actualen The Birtbday Party. Stan, tras ser "preparado" por Goldberg y McCann (emisarios de la sociedad conformista), queda convertido en un fantoche impecable pero incapaz de expresarse por sí solo. Esta coincidencia de ideas es completamente lógica, ya que las raíces dramáticas de Pinter también se nutren de Pirandello. 
sobre la realidad. De acuerdo con la técnica de la última vanguardia, Villaurrutia exhibe con una situación dramática $-\mathrm{y}$ no con métodos discursivos- esta faceta de la ideología pirandelliana. Además se aprecia una trasposición de los hechos fundamentales de Come tu mi vuoi de Pirandello. En esta obra La Desconocida es, en efecto, la impostora de Lucía, joven esposa raptada Io años antes (Villaurrutia emplea el mismo lapso de tiempo); pero es aceptada por la familia de Lucía porque se parece a una pintura de cómo era Lucía antes. Pese a imponerse inicialmente en el papel de la otra, La Desconocida fracasa también ante la tiranía de aquella imagen. No soporta estancarse en una forma preconcebida y ajena a su propia individualidad dinámica y por ello tiene que marcharse. En este caso es la realidad que triunfa sobre la ilusión.

Dos obras posteriores de Villaurrutia son menos sombrías, pese a su proximidad a la muerte prematura que tanto le obsesionaba. El yerro candente asimismo manifiesta la influencia pirandelliana mediante una trasposición de los hechos claves de Tutto per bene. En esta obra italiana Martino Lori se encuentra de repente en la sublime ridiculez al descubrir que Palma no es su hija, sino el fruto de los amores ilícitos de su difunta esposa, cuya memoria aun veneraba después de muerta. Sólo él ignoraba que su benefactor, Manfroni, era el progenitor de la niña, quien llegó a menospreciar a Lori por juzgarlo un hipócrita esclavizado a las apariencias. Al darse cuenta del amor sincero de Lori, ella públicamente rechaza a Manfroni a favor de aquél que siempre había sido un padre verdadero para ella.

En $\mathrm{El}$ yerro candente, en cambio, es la hija Antonia quien ignora su bastardía, ya que su padrastro la había acogido como hija suya al nacer. Villaurrutia suele edificar sobre la premisa pirandelliana. Por ello lleva el tema del sentimiento paterno a sus úlímas consecuencias al contraponer a la hijastra la presencia de una hija legitima. Lejos de preferir a su propia hija, el padre siente aún mayor afinidad espiritual con la hijastra, con la que no tiene ni siquiera parentesco sanguíneo. El padre fisiológico de Antonia, un primo disoluto de su madre, no provee por ella, como hace Manfroni por Palma; antes bien Ramón le extorsiona dinero a la madre a cambio de su silencio. Todos quedan cobardemente enmascarados - la madre, el padre y el padre "aparente"- ante el temor de que se descubra "la verdad desnuda" (398). Ramón, deshumanizado desde aquel momento en que había renunciado su derecho de paternidad, reacciona el día en que, por razones económicas, no se le puede dar más dinero. Esta crisis desata la pasión latente del padre arrepentido. Insiste en que Antonia sepa quién es su padre. Es de lo 
más inverosímil que Ramón espere que Antonia opte por unirse a él, casi un desconocido, traicionando asi el amor de quien siempre le habia. hecho de padre. El yerro candente confirma el sentimiento filial a lo pirandelliano, en que siempre domina la fuerza subjetiva. Por eso los lazos afectivos pueden más que los lazos sanguíneos (como se aprecia también en L'innesto) y la ilusión puede hacerse realidad, como en Tulto per bene (y en Il piacere dell"onestà).

Pirandello concibe uno de los episodios más intensos derivados de la obsesión en Quesha sera si recita a soggetto, donde un marido sicopático, Verri, encierra a Mommina a fin de ejercer un dominio absoluto sobre ella. Su celo culmina en la mayor desesperación al darse cuenta de su incapacidad de vigilar sus pensamientos; ni con sacarle los ojos podría borrar de su mente las imágenes de los hombres que ella había amado antes de entregarse a él. Tan exacerbados celós apenas encuentran eco en Juego peligroso de Villaurrutia. In la obra mexicana, personajes lúcidos, más que apasionados, revelan esta misma preocupación mediante diálogos calculados con frialdad. La imaginación juega un papel decisivo en motivar los celos que amenazan la disolución de un matrimonio. Bien que las sospechas de Irene se fundan en un indicio tangible de infidelidad -un anillo de mujer que se encuentra en su recámara al regresar de un viaje que ha hecho sin su esposo-, ella se venga incitando los celos de Arturo con suposiciones provocativas. Le insinúa que ella también podría engañarle, aunque fuera sólo con el pensamiento.

Arturo: ¡Pero todo esto es absurdo; absurdo por impensable!

Irene: Impensable, no...

Arturo: ¿Quieres decir que..?

Irene: Que nada es impensable; que del mismo modo que yo he podido pensar en que tú me has engañado; en que tủ me engañas...

Ya ves que nada es impensable!. Si lo estás pensando! Pero no te he engañado... Lo he pensado, lo pienso ahora...

Arturo: ¡Pero si no es posible!

Irene: Lo que te parecía impensable te parece ahora imposible. Y sin embargo, ya lo ves: se piensa lo impensable y lo imposible puede hacerse posible (488). 
Predomina nuevamente la imaginación sobre los hechos verídicos. Con sólo imaginarse adúltera, Irene se juzga "culpable". En efecto acaba pidiéndole el divorcio a Arturo, "ahora que aún es tiempo y que no soy culpable sino con el pensamiento..." (490).

Hay reminiscencias pirandellianas en otras obras de Villaurrutia. En La mujer legitima, por ejemplo, la primera esposa difunta de Rafael, según se le describe, parece la contrafigura del siciliano Verri. $\mathrm{O}$ acaso Villaurrutia se inspiró en la vida del mismo pirandello, acosado sin tregua por las sospechas locas de su esposa Antonietta, quien sólo después de muchos años fue internada. Cuando Sara trata en balde de imponerse como "la mujer legítima" (habiendo sido largo tiempo la amante de Rafael), procura vencer los prejuicios de sus nuevos hijastros revelándoles la locura de su madre cuando vivía. Esta "torturaba a Rafael con celos, con fantasías absurdas, con invenciones; gozando... con el martirio que daba a todos, hasta convertir la casa en un infierno..." (278). Tal había sido en efecto la tragedia de Pirandello.1l De la misma manera que el dramaturgo ítalo encontró por fin escape en la amistad de Marta Alba, protagonista de sus mejores obras teatrales, así Rafael se refugia en su amante, Sara. La locura ensombreció toda la existencia de Pirandello. La demencia persigue también a Rafael. Es cierto que la primera esposa muere, pero cuando piensa instalar a Sara legítimamente en el seno de su familia, descubre que su hogar sigue siendo el infierno de siempre: su hija ha heredado los síntomas de la madre demente.

Esta revisión de las obras más representativas de Villaurrutia comprueba el influjo ejercido por Pirandello en este dramaturgo mexicano. Como su antecesor siciliano en sus mejores obras, Villaurrutia desdeña lo tópico para explorar campos universales: la potencia de la imaginación humana, así como conceptos de la paternidad y del hombre existencial. Aun cuando edifica sobre situaciones pirandellianas, es obvio que Villaurrutia se aparta del maestro italiano, en su afición por el equilibrio y lo enigmático, razones éstas por las que está dispuesto a sacrificar la humanidad de sus personajes. Estos sirven meramente de instrumentos maquinales a la exposición conceptualista de su autor. En ningún momento se perciben los rasgos improvisados que caracterizan ciertas obras

11 El biógrafo de Pirandello dice que Antonietta no le dejó vivir. Apenas le permitió escuchar de la vida l'eco infernale. Federico V. Nardelli, Vita segreta di Pirdadello (Italia, 1926), p. 170. 
de Pirandello. Más que cronológicamente, por su estilo y sus recursos, Villaurrutia ocupa un lugar intermedio entre Pirandello y los más recientes dramaturgos universales que hacen del teatro un espectáculo de goce intelectual destinado a las minorias.

University of California

Alyce de Kuehne

Santa Bárbara 